\title{
LITERATURA E ORALIDADE NO CORDEL: IDENTIDADE E MEMÓRIA CULTURAL NORDESTINA
}

\section{LITERATURA Y ORALIDAD DE CORDEL: IDENTIDAD Y MEMORIA CULTURAL NORDESTINA}

Osmando J. Brasileiro'

Regina da Costa da Silveira²

Resumo: As narrativas orais remontam à antiguidade grega, como a célebre Odisseia, de Homero, que se tem conhecimento como umas das grandes obras ocidentais que mais influenciaram a nossa cultura literária. $O$ presente trabalho estuda a oralidade e a identidade da memória cultural nordestina em textos da tradição oral e também tece reflexões a respeito do conceito de identidade e memória, com base em teóricos como Idelette Muzart-Fonseca dos Santos (2006), Hall (2004), e Le Goff (2003), com aplicação dos conceitos na análise de textos de Patativa do Assaré, João Ubaldo Ribeiro, dentre outros.

Palavras-chave: Literatura; Memória das vozes; Cordel.

Resumen: La narrativas orales se remontan a la antigüedad griega, como la célebre Odisea, de Homero, que se conoce como una de las grandes obras occidentales que más influyen en nuestra cultura literaria. En este trabajo se estudia la oralidad e identidad de la memória cultural nordestina en textos de la tradición oral y también teje reflexiones sobre el concepto de la identidad y memoria, con base en los teóricos: Idelette Muzart-Fonseca dos Santos (2006), Hall (2004), Le Goff (2003) y con la aplicación de los conceptos en el análisis de textos de Patativa do Assaré, João Ubaldo Ribeiro y otros.

Mestrando bolsista institucional em Letras do Centro Universitário Ritter dos Reis UNIRITTER. osmando.brasileiro@ig.com.br. Endereço: Rua Orfanotrófio, 555, Auto Teresópolis, Porto Alegre, RS.

2

Doutora em Literatura e professora do Centro Universitário Ritter dos Reis - UNIRITTER. regina.flausina@gmail.com. Endereço: Rua Orfanotrófio, 555, Auto Teresópolis, Porto Alegre, RS. 
Palabras claves: Literatura; Memoria de las voces; Cordel.

\section{Introdução}

As narrativas orais remontam à antiguidade grega, como a célebre Odisseia, de Homero, uma das grandes obras ocidentais que mais influenciaram a nossa cultura literária. A tradição oral medieval tem início no Brasil com a colonização a partir de 1500, ambientou-se no Nordeste brasileiro pelas semelhanças geográficas dessa região com os cenários medievais da época. No Brasil, a tradição oral se apresenta de várias formas, contudo, a literatura de cordel é a que mais tem resistido e é a maior detentora de um cabedal de informações passadas na forma de expressões rimadas, com características específicas, que instigam os cantadores a memorizarem seus longos poemas. Essa tradição tem como um dos seus mais importantes expoentes o cordelista cearense Patativa do Assaré ${ }^{3}$, autor do conhecido poema musicado por Luiz Gonzaga, A triste partida (1966), em que conta as agruras do sofrimento causado por conta da seca nordestina.

Essa tradição literária oral representa um importante meio de resguardar a memória popular nordestina com a transformação de temas cotidianos em canções rimadas a serem divulgadas em feiras e folhetos de cordel, como é comum em cidades da Região Nordeste, a exemplo de Campina Grande na Paraíba. A memória do cordel é um importante instrumento da identidade cultural nordestina que eleva a estima popular como parte da constituição de uma identidade nacional brasileira. O objetivo do presente trabalho é tecer reflexões acerca da cultura popular oral nordestina presente em folhetos de cordel e em textos literários de prosa, como aparece na obra Viva o povo brasileiro, de João Ubaldo Ribeiro, e também identificar elementos da cultura oral a partir de trechos de cordéis analisados no decorrer dos estudos sobre esta literatura.

Dentre os teóricos utilizados, destaca-se Stuart Hall, com os conceitos sobre identidade em A identidade cultural na pós-modernidade (2004). Segue-se Idelette MuzartFonseca dos Santos, a partir de seu texto Memória das vozes: cantoria, romanceiro \& cordel (2006) que discorre sobre a história dos cordéis, a preservação da memória por meio da voz 3

Mais informações sobre o autor cearense são encontradas em Nonada Letras em Revista, Editora UniRitter. O no 13 traz um dossiê dedicado aos 100 anos de nascimento do cordelista. Disponível em http://seer.uniritter.edu.br/index.php/nonada/article/viewFile/184/118. Acesso em 14 de out. 2013. 
poética e dos cancioneiros populares no Brasil; e Ana Maria de Oliveira Galvão, com sua obra: Cordel: leitores e ouvintes (2006), em que analisa o caminho da narrativa de cordel, demonstrando-a como enciclopédia para o leitor e resguardadora da memória popular nordestina. Importante sugestão de leitura chega-nos do IELT, Universidade de Lisboa. Tratase do livro Os Monstros na Literatura de Cordel Portuguesa do século XVIII, de Ana Margarida Ramos, v. 23, das Edições Colibri. Nesse livro, a autora destaca o papel primordial que a oralidade desempenha no âmbito da literatura tradicional e das suas origens, observando influências mútuas entre o oral e o escrito em várias culturas e em várias épocas. Assim, textos que antes circulavam oralmente, de geração em geração, tornam-se parte não apenas do patrimônio cultural, mas passam para o domínio literário, dito canônico, ao passo que "Temas e motivos da literatura de elite cristalizam-se no tempo e são recuperados e adaptados pela tradição popular que os adopta e quase venera, destruindo fronteiras que se pensavam intransponíveis." (RAMOS, 2008, p. 42).

\section{Memória e identidade nas produções orais}

As sociedades atuais se fundamentam por meio de sua memória conservada nas tradições, mas o que é então a memória? Na definição de memória, servimo-nos de Le Goff (2003), para quem o termo "memória" surge em seus fundamentos teóricos das ciências humanas, da história e da antropologia, afirma o medievalista:

A memória, como propriedade de conservar certas informações, remete-nos em primeiro lugar a um conjunto de funções psíquicas, graças às quais o homem pode atualizar impressões ou informações passadas, ou que ele representa como passadas. (p. 423)

Após fazer um histórico do termo, passando pela psicologia, teorias da aprendizagem de Piaget entre outros, Le Goff reafirma a possibilidade de a memória ser individual e coletiva.

No caso brasileiro, essa memória é formada também pela questão da tradição que remonta à chegada dos europeus no Brasil em várias regiões, como é o caso do Nordeste, região cuja identidade é também fruto da herança de antepassados, no caso do cordel nordestino, uma herança que remonta ao período colonial brasileiro. Assim,

No Brasil e em países como na França, o cordel que provém da Região Nordeste vem ocupando espaço privilegiado como gênero artístico-literário. Os versos 
apresentam-se em forma de poesia rimada, e quando sua performance ocorre via oral (canção) e gestual (representação), a literatura de cordel ganha vida e contribui ainda mais para propagar as histórias e narrativas populares do Nordeste brasileiro, que são autênticas manifestações de oralidade. (SILVEIRA e FREITAS, 2009, p. 3)

A partir desses pressupostos, presume-se que a identidade nordestina está resguardada em seus ritos e tradições mantidas até hoje em forma de canções populares. Como exemplo dessas canções, dentre as mais conhecidas, temos a Literatura de Cordel, que é assim denominada por conta de sua fabricação artesanal e para sua comercialização, os folhetos são expostos em cordões nas feiras com a recitação de trechos pelo autor, como forma de divulgar seu produto e atrair o consumidor. Estes textos trazem elementos que são parte constitutiva do cotidiano das pessoas que os consomem, fato importante na obtenção de leitores, mas sua importância não se restringe apenas à representação de temas do cotidiano, trata-se de uma literatura que reúne a história de indivíduos e abrange temas universais, consolidando a identidade de comunidades inteiras, o que em muito contribui para a conservação da memória cultural nordestina.

A identidade é constituída e preservada, também, por meio da tradição de um determinado povo ou cultura. Dessa forma, nossa concepção de identidade segue a definição de Hall (2007), pois segundo ele, a identidade não pode ser definida de forma simples:

Uma vez que a identidade muda de acordo com a forma como o sujeito é interpelado ou representado, a identificação não é automática, mas pode ser ganhada ou perdida. Ela tornou-se politizada. Esse processo é, às vezes, descrito como constituindo uma mudança de uma política de identidade (de classe) para uma política de diferença. (p. 21).

Se a identidade, segundo Hall (2007), deve ser construída pela própria pessoa ou grupo de pessoas, uma vez que ela se firma centrada na diferença, assim, abre-se a possibilidade para ver as representações veiculadas nos folhetos de cordel como detentoras de uma identidade cultural nordestina. Observa-se, então, que a preservação dessa cultura nordestina, com a manutenção de suas tradições por meio da cultura oral, auxilia na constituição da identidade do Nordeste como lugar dos poetas populares, cantadores de sua própria história.

É a partir daí que se consegue visualizar que as vozes cantadas no sertão possuem uma história e nela deixam transparecer suas tradições, vivências passadas de geração a geração. A preservação dessa memória é importante no fortalecimento da construção identitária do povo nordestino, bem como auxilia na interpretação das representações sobre esse sujeito. Assim, 
Memória das vozes pretende ser uma ajuda à compreensão destas vozes que vêm do passado e continuam vivas no presente, vozes poéticas e cantadas, ou "traduzidas" para a escrita quando a simples memória enfraquece e se revela insuficiente para conservar a riqueza do patrimônio poético. (MUZARTE-FONSECA, 2006, p. 15).

Marcado pela oralidade, o patrimônio poético nordestino tem suas marcas na escrita reveladas por formas que abrangem tanto a forma do cordel escrito como suas apresentações orais. Nas reproduções em narrativas, também se encontram trechos recolhidos da oralidade, é o caso do romance Viva o povo brasileiro, de João Ubaldo Ribeiro, como veremos adiante. Interessante observar que mesmo em sua transposição para a escrita esses trechos caracterizam-se como falas, conservando marcas perceptíveis da oralidade. Trata-se de uma hipótese, antes lançada por Ana Maria Galvão, em forma de questionamento: "Mas, além de trazerem características que os assemelham às narrativas orais no próprio caminho narrativo utilizado pelo poeta na elaboração do poema, como outras marcas da oralidade estão presentes em sua composição?” (GALVÃO, 2006, p.76). São, pois, marcas da fala, por exemplo, a falta de concordância típica do falar popular nordestino na qual o plural é feito apenas nos artigos, por exemplo: "os menino", dentre outras. Não obstante exista aqui uma transgressão da norma culta, são expressões que mantêm a informação de que se trata do plural, uma característica da fala nordestina, que está pautada em sua cultura e tradição.

A palavra tecnologizada permitiu o registro da cultura oral, conforme nos diz Walter Ong (1998), possibilitando à cultura popular se firmar não apenas como registro oral, mas também como texto escrito, fortalecendo ainda mais sua identidade. Por conta dessas especificidades, a literatura de cordel não é uma simples transcrição, mas o registro da memória cultural popular. Sobre o assunto, Galvão (2006) considera que:

Como mostram os estudos sobre História da Leitura, esses "índices de oralidade" não se constituem em representações de práticas de oralidade, mas se referem aos dispositivos depositados nos textos, explícitos ou implícitos, que conferem a eles uma destinação oral. (p. 76).

\section{Marcas da oralidade e da memória em Viva o povo brasileiro e $A$ triste partida}

No romance Viva o povo brasileiro, a representação da memória popular coletiva é transcrita em seus aspectos jocosos, o que confere à narrativa de João Ubaldo Ribeiro fidedignidade ainda maior em relação aos registros sobre identidade e memória popular na 
literatura brasileira. Longe de observar o viés limitador da moralidade que não prevê a violação do sagrado pelo profano, o texto em seu conteúdo e forma é revelador da criatividade lúdica e ordinariamente popular:

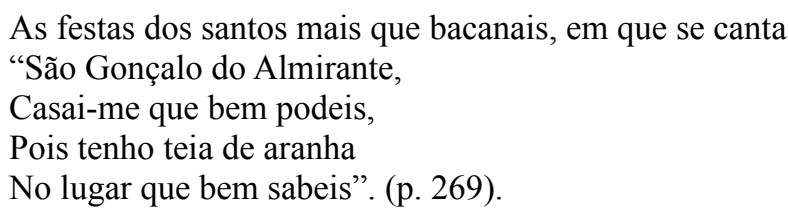

A veia satírico-literária, por seu turno, lembra em muito Gregório de Matos Guerra, o Boca do Inferno. No exemplo que segue, verifica-se a linguagem grotesca do conteúdo profano em orações religiosas, na voz de mulheres que vão à igreja:

"São Gonçalo vem do Douro,

Traz uma carga de couro,

Do que mais estica,

O qual é couro de pica". (sic, p. 269).

Como se da autoria desses trechos o próprio autor do romance abdicasse, os versos vêm transcritos entre aspas no romance, tal como se registra o discurso do outro, sabendo-se que é apócrifo por vezes o discurso cuja recolha se faz diretamente da oralidade.

Os versos transcritos pelo narrador de forma satírica servem para ilustrar que a igreja, embora seja um lugar exclusivo do sagrado $^{4}$, caracteriza-se como um espaço em que as pessoas verbalizam orações em rituais ou podem mesmo rezar em silêncio, buscando acima de tudo a realização dos desejos humanos, ainda que os mais recônditos.

A oralidade preserva também heranças culturais dos tempos da escravidão, já que a literatura de cordel é registrada desde o século XIX em forma de disputas pelos escravos, que se tornavam cantadores e assim obtinham favores ou negociavam sua própria liberdade por meio dos dons artísticos ao mesmo tempo em que registravam e preservavam sua memória, assim,

Os grilhões da escravidão não congelaram a alma, nem paralisaram o pensamento dos Mandinga, Ioruba, Banto, Fanti, Axanti, Ewê-Fon ou Akan. É a hora de esquecer o esquecimento. A memória existe e há memórias que surgem em contos e relatos, em mitos e crenças, em toques e silêncios de tambores. Também no gesto, na dança e na ética do viver ou do morrer. (MONTIEL, 1999, p. 28).

4

Sobre o espaço sagrado e profano da igreja pode-se ver ELIADE, Mircea. O Sagrado e o Profano: a essência das religiões. São Paulo Martins Fontes, 1998. 
A oralidade do cordel registra a herança massacrada da escravidão e mantém a resistência ao buscar alternativas de preservação de sua memória e história por meio da tradição oral.

A partir dessas reflexões, observa-se que a literatura oral não é apenas detentora de aspectos da oralidade, mas ela está presente em outras formas de textos como os imagéticos que expressam falas e anedotas típicas da oralidade por meio de grafites, muito comuns em charges e HQ. É necessário se pensar também que a escrita surge da oralidade, quando se sente a necessidade de preservar por meio do registro escrito o que está sendo dito, e dessa forma, inevitavelmente traz seus aspectos nos registros escritos. Por conseguinte, a importância da oralidade é fundamental na leitura dos contos de fadas, mesmo por que eles foram produzidos com o intuito de serem recitados para as crianças, dessa forma, Cecília Meireles (1984) diz que,

não se pode pensar numa infância a começar logo com gramática e retórica: narrativas orais cercam a criança da Antiguidade, como as de hoje (...). Assim, mitos, fábulas, lendas, teogonias, aventuras, poesia, teatro, festas populares, jogos, representações várias' ocuparam, no passado, o lugar que hoje concedemos ao livro infantil. (...) quase se lamenta menos a criança de outrora, sem leituras especializadas, que as de hoje, sem os contadores de histórias. (p. 55).

A Literatura de cordel também é fonte de trabalho, protesto, resistência, informação e lazer, são textos que conferem vida às feiras nordestinas, seja animando-as com as cantorias dos cordelistas, seja garantindo-lhes o ganha-pão. Para ilustrar algumas funções dessa literatura popular, recorremos ao célebre poeta cearense Patativa do Assaré.

Fig. 1 - Patativa do Assaré - Museu Dragão do Mar - Fortaleza

Antônio Gonçalves da Silva, pseudônimo Patativa do Assaré ${ }^{5}$ nasceu em 5 de março de 1909, na cidade de Assaré no estado do Ceará. Foi um dos mais importantes representantes

5

Para ilustração, o link http://www.youtube.com/watch?v=IUQlevclt1w, disponibiliza o cantar e as imagens do lindo pássaro, em alusão ao qual o poeta cearense recebera parte do apelido. 
da cultura popular nordestina por meio de suas produções em forma de literatura de cordel $^{6}$, também manteve em suas poesias o falar típico do nordestino do campo.

Suas poesias ficaram conhecidas por conta do apelo que faz referência ao sofrimento da população decorrente das longas estiagens nordestinas. Algumas delas tornaram-se letras de músicas que ganharam o Brasil na sanfona de Luiz Gonzaga (2013), o Rei do Baião, o caso mais conhecido é $A$ triste partida, musicada em 1966.

Assim inicia a poesia:

\author{
Meu Deus, meu Deus. . . \\ Setembro passou \\ Outubro e Novembro \\ Já tamo em Dezembro \\ Meu Deus, que é de nós, \\ Meu Deus, meu Deus \\ Assim fala o pobre \\ Do seco Nordeste \\ Com medo da peste \\ Da fome feroz \\ Ai, ai, ai, ai
}

O apelo a "Deus" é típico do falar nordestino, que respeitosamente pede ajuda na hora do sufoco de qualquer natureza, por isso traz uma representação forte da oralidade do povo do campo. Seguido da narração de que os tempos das chuvas estão passando e ela não veio, junto a isso se somam os problemas que se acumulam, como fome e doenças advindas das péssimas condições de salubridade e da própria falta de água.

Nos versos seguintes se percebe que em muitos casos é preciso fugir, e o maior campo de fuga são as cidades grandes, pois mesmo vivendo nas favelas das cidades grandes é, para muitos nordestinos, melhor do que sofrer com a falta d'água e o descaso político do sertão. Como se observa nos versos seguintes de $A$ triste partida

\footnotetext{
Nós vamos a São Paulo

Que a coisa tá feia

Por terras alheia

Nós vamos vagar

Meu Deus, meu Deus

Se o nosso destino

Não for tão mesquinho
}

6

$$
\text { Informações disponíveis no sítio: }
$$

http://www.suapesquisa.com/biografias/patativa_assare.htm>, acesso, em og de out. 2013. 
Todas as estrofes terminam com o verso "Ai, ai, ai, ai”, reforçando a ideia do sofrimento passado pelas pessoas que vivem no contexto da seca do Nordeste Brasileiro.

Chegando na cidade grande sentem então o choque de se está em território alheio, em que os elementos da identidade se tornam frágeis e é necessário a imersão no conhecimento do outro na tentativa de se estabelecer como elemento estranho a esse lugar, daí que surge a necessidade de sujeição de qualquer forma para conseguir a sobrevivência. Mas também se mantém, em meio a tanto sofrimento e exploração, a esperança de retornar à terra natal, os versos que encerram a poesia também revelam tal esperança:

$$
\begin{aligned}
& \text { Distante da terra } \\
& \text { Tão seca mas boa } \\
& \text { Exposto à garoa } \\
& \text { À lama e o paul } \\
& \text { Meu Deus, meu Deus } \\
& \text { Faz pena o nortista } \\
& \text { Tão forte, tão bravo } \\
& \text { Viver como escravo } \\
& \text { No Norte e no Sul } \\
& \text { Ai, ai, ai, ai }
\end{aligned}
$$

A tradição oral nordestina não está presente apenas no Nordeste, há estudos que comprovam a máxima de que por onde vão os nordestinos levam com eles sua tradição, a exemplo dos estudos sobre a tradição nordestina em São Paulo, expressos em Aprendendo a aprender a cultura popular, de Maria Ignez Novais Ayala (2011). Nesse artigo, a autora mostra que a cultura do imigrante nordestino ganha outra dimensão na cidade grande, mas se preserva, conservando um viés saudosista e a esperança de retorno à sua terra de origem.

\section{Considerações (quase) finais}

Quando se conhece a realidade nordestina, percebe-se que o que a mídia veicula nem sempre é condizente com a realidade. É verdade que existem pontos específicos da região com a aridez do solo, com o grave problema da seca, mas também, constata-se a presença de terras férteis e abundantes, a existência do turismo como fonte de renda favorável na zona do litoral. Contudo, a seca é o que mais causa sofrimento ao povo brasileiro, tema veiculado pela arte literária de Patativa do Assaré, que expressa a negligência e o descaso do homem da 
cidade, insensível diante da situação precária do homem da roça. São fatos que remetem o leitor menos ingênuo à ação inconsequente de alguns políticos, com o desvio de investimentos direcionados para suprir a falta de água na região, por meio da chamada Indústria da Seca, ação abominável que sobrepõe indignação ao sofrimento popular.

No perfil identitário do povo nordestino, somam-se, portanto, as diferenças marcadas pelas desigualdades sociais, acentuadas pela má distribuição de renda. Todos esses infortúnios são temas que compõem a arte de fazer versos, sedimentando a tradição oral da cultura popular nordestina. Graças à voz dos cantadores, esses temas têm sido apregoados de modo a atingir um grande número de leitores, constituindo-se no chamado de atenção para as necessidades mais imediatas que vêm de longa data persistindo na composição da memória desse povo.

Como se observou neste ensaio, a tradição oral nordestina mescla temática social, ambiental, econômica, religiosa e política em suas produções poéticas. Em seu conjunto, esses elementos temáticos da literatura de cordel se universalizam porque tratam da condição humana, ao mesmo tempo em que são parte integrante da identidade cultural e da memória nordestina brasileira.

\section{REFERÊNCIAS}

AYALA, Maria Ignez Novais. In: PINHEIRO, Hélder (org.). Pesquisa em literatura. 2 ed. Campina Grande: Bagagem, 2011.

BERGSON, Henri. Matéria e Memória. São Paulo: Martin Fonte. 1990.

GALVÃO, Ana Maria de Oliveira. Cordel: leitores e ouvintes. 1. ed. Belo Horizonte: Autêntica, 2006.

GONZAGA, Luiz. A triste partida: letra e música. Disponível em

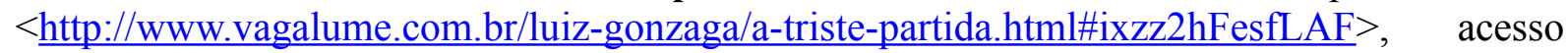
em, 09 de out. de 2013.

LE GOFF, Jacques. História e Memória. Trad. Bernardo Leitão... [et al.]. 5 ed. Campinas: Editora da UNCAMP, 2003. 
MEIRELES, Cecília. Problemas da literatura infantil. 3.ed. Rio de Janeiro: Nova fronteira, 1984.

MONTIEL, Luz Maria Martínez. Oralidade. México: Programa África-América - A $3^{\mathrm{a}}$ Raíz, 1999. (Etnologista).

ONG, Walter. Oralidade e cultura escrita: a tecnologização da palavra. Campinas: Papirus, 1998.

RAMOS, Ana Margarida. Os Monstros na Literatura de Cordel Portuguesa do século XVIII. Lisboa: IELT, Edições Colibri, 2008.

RIBEIRO, João Ubaldo. Viva o povo brasileiro. Rio de Janeiro: Nova Fronteira, 1984.

RICOEUR, Paul. A memória, a história, o esquecimento. Tradução, Alain Francois [et al.]. Campinas: Editora da Unicamp, 2007.

SANTOS, Idelette Muzart-Fonseca dos. Memória das Vozes: cantoria, romanceiro e cordel. Prefácio de Armindo Bião - Tradução de Márcia Pinheiro. Salvador: Secretaria da Cultura e Turismo, Fundação Cultural do Estado da Bahia, 2006.

SILVEIRA, Regina da Costa da e FREITAS, Roberta Moreira. Memória popular: Patativa estende seus barbantes além, muito além do Ceará. In: NONADA, $\mathrm{n}^{\circ} 13,2009$. Disponível em: $<$ http://seer.uniritter.edu.br/index.php/nonada/article/viewFile/184/118 $>$, acesso em 14 de out. 2013. 